\title{
Academic motivation scale - reliability and validity evidence among undergraduate nursing students*
}

\author{
Geisa Colebrusco de Souza ${ }^{1}$ \\ (1D) https://orcid.org/0000-0003-4714-9462 \\ Everson Meireles ${ }^{2}$ \\ (D) https://orcid.org/0000-0002-1715-006X \\ Vera Lúcia Mira ${ }^{3}$ \\ (D) https://orcid.org/0000-0002-5896-3948 \\ Maria Madalena Januário Leite ${ }^{3}$ \\ (iD) https://orcid.org/0000-0002-3103-5084
}

Paper extracted from doctoral dissertation "Motivation and autonomy of nursing undergraduate students in the light of Self-Determination Theory", presented to Universidade de São Paulo, Escola de Enfermagem, São Paulo, SP, Brazil. 1 Universidade Federal de São Paulo, Escola Paulista de Enfermagem, São Paulo, SP, Brazil.

2 Universidade Federal do Recôncavo da Bahia, Centro de Ciências da Vida, Santo Antônio de Jesus, BA, Brazil.

3 Universidade de São Paulo, Escola de Enfermagem, São Paulo, SP, Brazil.
Objective: to assess the evidence of validity and reliability of the academic motivation scale (AMS) based on the internal structure. Method: this is a methodological study with 205 undergraduate nursing students. Dimensionality/internal structure of the AMS was assessed using factor analysis in the context of exploratory structural equation modeling (ESEM) and reliability of the factors was assessed by Cronbach's alpha (a) coefficient and composite reliability (CR) coefficient. Results: acceptable fit indexes were obtained (CFI $=0.92$; RMSEA = 0.07 ; SRMR $=0.06)$ for a three-dimensional model: intrinsic motivation ( 10 items; $a=0.84 ; C R=0.86$ ); extrinsic motivation ( 8 items; $a=0.84 ; C R=0.90$ ); and demotivation ( 4 items; $a=$ $0.84 ; C R=0.88)$. A significant correlational pattern was found for the motivation continuum. Conclusion: the dimensionality analysis for the AMS presented a model with three factors: intrinsic motivation, extrinsic motivation and demotivation, and was considered a reduced alternative to the original version of seven factors. This study helped assess the validity of the measurement instrument and its theory refinement; further studies should be conducted to assess its invariance property.

Descriptors: Motivation; Education, Nursing, Baccalaureate; Validation Studies; Reproducibility of Results; Factor Analysis, Statistical; Psychometrics.

\section{How to cite this article}

Souza GC, Meireles E, Mira VL, Leite MMJ. Academic motivation scale - reliability and validity evidence among undergraduate nursing students. Rev. Latino-Am. Enfermagem. 2021;29:e3420. [Access $\frac{1}{1} \frac{1}{1}$ ]; Available in: . DOI: http://dx.doi.org/10.1590/1518-8345.3848.3420. 


\section{Introduction}

According to the self-determination theory (SDT), motivation can be analyzed as a complex and multidimensional theoretical construct. The types of motivation can explain the different reasons why people act in a certain way, based on different types of regulation and causal locus of behavior. Motivation is considered autonomous when an action takes place due to a genuine interest in the activity, while the most controlled types of motivation occur when there is internal or external pressure to engage in an activity. The SDT also includes demotivation, that is, the absence of any type of motivation ${ }^{(1-5)}$.

Based on the SDT, Canadian researchers developed the Echelle de Motivation en Education (EME) in French(6), which was translated into English, validated and renamed as the Academic Motivation Scale (AMS) ${ }^{(7)}$. This scale was developed to measure the motivation level of students and their self-perception of the reasons for engaging in an activity ${ }^{(6-8)}$. In the academic context, students are expected to have the most autonomous types of motivation, as studies have demonstrated positive relations between these autonomous types and student performance ${ }^{(3-5)}$.

In comparison with the theoretical construct of the SDT, the scale included seven factors of specific taxonomy for the educational context: intrinsic motivation to know, to accomplish things, and to experience stimulation; extrinsic motivation by external, introjected, and identified regulation. Factor seven refers to demotivation. Extrinsic motivation by integrated regulation was suppressed in the AMS because, in the factor analysis, it is not distinguished from motivation by identified regulation ${ }^{(7-8)}$.

The AMS has been translated into several languages $^{(9-13)}$ and used in different educational contexts ${ }^{(14)}$ and different times, either in its original version with all items or versions including new items, which resulted in a modified instrument ${ }^{(15-16)}$. Several studies have assessed its psychometric properties ${ }^{(6-7,9-10,12-21)}$, confirming the theoretical model with seven factors through a confirmatory factor analysis (CFA) ${ }^{(6-7,9-10,12-15,17-19)}$ or rejecting it and presenting alternative models $^{(11,16,20-21)}$ with a different number of factors. Some of these studies did not demonstrate a correlation between the subscales (motivation continuum) $)^{(7-8,18-20,22)}$, i.e., no simple, positive strong correlation pattern was found between the adjacent types of motivation ${ }^{(1-2)}$.

In this sense, the first assessment of the AMS dimensionality showed inconsistencies in the exploratory factor analysis (EFA) and did not reproduce the theoretical model with seven subscales, with eigenvalues above one in at least one of the factors ${ }^{(6)}$. In the scale applied in
Canada, the CFA admitted the 7-factor structure of the theoretical model inadequately reproduced the observed covariance matrix; however, fit indexes increased after the inclusion of 26 residual correlations based on the modification indexes( ${ }^{(7)}$.

Later, the AMS showed concurrent validity with other motivation measurement instruments, with an appropriate correlation between the subscales regarding the hypothesis of motivation continuum postulated in the SDT, except for intrinsic motivation for stimulating activities, which showed a weak correlation(8).

In Brazil, the scale was translated into Portuguese(23) and applied to medical students; however, no robust analysis has assessed its dimensionality and reliability as an instrument to measure motivation. Although accepted in national studies ${ }^{(15,17,21)}$, since it was developed, new guidelines for the assessment of psychometric properties, translation and adaptation of instruments have been incorporated into the literature ${ }^{(24-25)}$. Therefore, processes must be adopted to evaluate its properties to ensure a valid and reliable scale for the measurement of academic motivation.

The stages of validation and evaluation of psychometric instruments must be performed in a continuous process to provide valid current reliable data about the measurement instruments(24). In view of the above, this study aimed to assess the evidence of validity of the academic motivation scale based on the internal structure $^{(26)}$ and the reliability indexes of the proposed dimensions of measurement.

\section{Method}

This is a methodological study conducted with undergraduate nursing students from a public university in the state of São Paulo in the second half of 2014. It used a convenience sample, which consisted of students who were available to participate in the investigation.

Considering the scarcity of evaluations about the factor structure of the AMS in the Brazilian context, the author decided to use the version translated from English(7) into Portuguese ${ }^{(23)}$, maintaining all items of the original version. The authors of this instrument authorized to use it for educational purposes ${ }^{(7)}$.

The original version of the AMS proposes to analyze motivation in the academic context, covering 28 propositions divided into seven subscales with four items each, scored on a Likert scale from 1 (no agreement) to 7 (total agreement), with a mean of 4 (moderate correspondence $)^{(7,23)}$. A student indicates the agreement with a statement, allowing the calculation of each type of motivation based on the items linked with the proposed theoretical construct, according to Table 1. 
Table 1 - Type of motivation and items related to the original constructs of the academic motivation scale (AMS). São Paulo, SP, Brazil, 2014

\begin{tabular}{|c|c|c|c|}
\hline \multicolumn{2}{|c|}{$\begin{array}{c}\text { Type of motivation (motivation } \\
\text { continuum) }\end{array}$} & \multirow{2}{*}{$\begin{array}{c}\text { Items } \\
\begin{array}{c}\text { related to } \\
\text { the original } \\
\text { construct }\end{array} \\
02 ; 09 ; 16 ; 23\end{array}$} & \multirow{2}{*}{$\begin{array}{r}\text { Score } \\
1-7\end{array}$} \\
\hline \multirow{3}{*}{$\begin{array}{l}\text { Intrinsic } \\
\text { motivation }\end{array}$} & To know & & \\
\hline & $\begin{array}{l}\text { To accomplish } \\
\text { things }\end{array}$ & $06 ; 13 ; 20 ; 27$ & $1-7$ \\
\hline & $\begin{array}{l}\text { To experience } \\
\text { stimulation }\end{array}$ & $04 ; 11 ; 18 ; 25$ & $1-7$ \\
\hline \multirow{3}{*}{$\begin{array}{l}\text { Extrinsic } \\
\text { motivation }\end{array}$} & $\begin{array}{l}\text { Identified } \\
\text { regulation }\end{array}$ & $03 ; 10 ; 17 ; 24$ & $1-7$ \\
\hline & $\begin{array}{l}\text { Introjected } \\
\text { regulation }\end{array}$ & $07 ; 14 ; 21 ; 28$ & $1-7$ \\
\hline & External regulation & $01 ; 08 ; 15 ; 22$ & $1-7$ \\
\hline Demotivation & $\begin{array}{l}\text { Absence of } \\
\text { motivation }\end{array}$ & $05 ; 12 ; 19 ; 26$ & $1-7$ \\
\hline
\end{tabular}

Source: Developed by the author based on the 7-factor model originally proposed by Vallerand, et al..$^{(6,7)}$ and translated into Portuguese by Sobral ${ }^{(23)}$

In addition to the score for each of the seven types of motivation, three different factors were defined at a higher order of the scale ${ }^{(6-8,17,21)}$ : Intrinsic Motivation, Extrinsic Motivation, and Demotivation, based on the arithmetic mean calculation.

Data were collected at formal times of academic activity after obtaining the authorization of coordinators and professors of the course who indicated the best moment for the researcher to explain the study participation. The students who agreed to participate remained in the room to answer the instrument and sign an informed consent form (ICF), which was returned to the researcher. The instrument had no student identification to ensure data confidentiality.

Data were organized in Microsoft Office Excel spreadsheets and factor analyses were performed using the exploratory structural equation modeling (ESEM)(27), whose source of information was a polychoric correlation matrix. The methods of weighted least squares means and variance (WLSMV) estimation and GEOMIN oblique rotation were adopted. These analyses were conducted using the Mplus $7^{(28)}$ and the number of factors to be extracted was indicated by parallel analyses( ${ }^{(29)}$. The criterion for maintaining an item in the instrument was defined a priori: saturation of factor load $\geq 0.40$ and item-total correlation $\geq 0.40$.

Estimated factor solutions were evaluated based on theoretical reasonability, interpretation of factors according to theoretical assumptions ${ }^{(7)}$, and degree of factor model adjustment to the empirical data. The following criteria were considered: a comparative fit index (CFI) above 0.90 indicated good adjustment; root-mean-square error of approximation (RMSEA) and standardized root-mean-square residual (SRMR) values below 0.08 indicated adjustments in these two residual indices, and values below $0.06^{(30-31)}$ were considered desirable. Factor reliability was assessed by Cronbach's alpha and composite reliability coefficients, with values of 0.70 or above considered satisfactory indicators in exploratory studies ${ }^{(32-33)}$.

This study was approved by the Research Ethics Committee (Certificado de Apresentação de Apreciação Ética - CAAE 45542415.7.0000.5392) and by those in charge representing the institution and was conducted according to the ethical practices for research with human beings.

\section{Results}

This study analyzed 205 instruments, which were filled out by $68.5 \%$ of all students enrolled in the nursing course. Of these, $32.7 \%$ were from the 1 st year of the course $(N=67), 26.8 \%$ from the $2^{\text {nd }}$ year $(N=55), 22.9 \%$ from the $3^{\text {rd }}$ year $(\mathrm{N}=47)$, and $17.6 \%$ from the $4^{\text {th }}$ year $(\mathrm{N}=36)$. Mean age of the students was $21.7(\mathrm{SD}=3.81)$, median of 21 (range $18-45$ years), and $62.4 \%(\mathrm{~N}=128)$ were aged 18 to 22 years. Most were female students, corresponding to $88.29 \%(\mathrm{~N}=181)$.

Initially, the results of parallel analyses indicated the pertinence of extracting up to three factors and did not support the extraction of seven factors, as proposed in the original theoretical model illustrated in Figure 1. After the third factor, any values in a random data matrix would be able to produce eigenvalues above the empirical eigenvalues.

Considering this indication, factor analyses were performed with extraction of one, two and three factors. The adjustment results of these models were: onedimensional model (CFI $=0.68$; RMSEA $=0.14$; SRMR $=0.16) ; 2$-factor model ( $C F I=0.82 ;$ RMSEA $=0.11$; SRMR $=0.11$ ), and 3-factor model (CFI $=0.92$; RMSEA $=0.07 ; \mathrm{SRMR}=0.06)$. Only the 3 -factor solution demonstrated an acceptable fit according to the criteria indicated for the structural model (RMSEA <0.08; SRMR $<0.06$; and CFI >0.90). Also, the 3-factor solution came close to the theoretical expectations after grouping the items, according to the original model of the scale, which provides three factors of a higher order (Intrinsic Motivation, Extrinsic Motivation and Demotivation). 


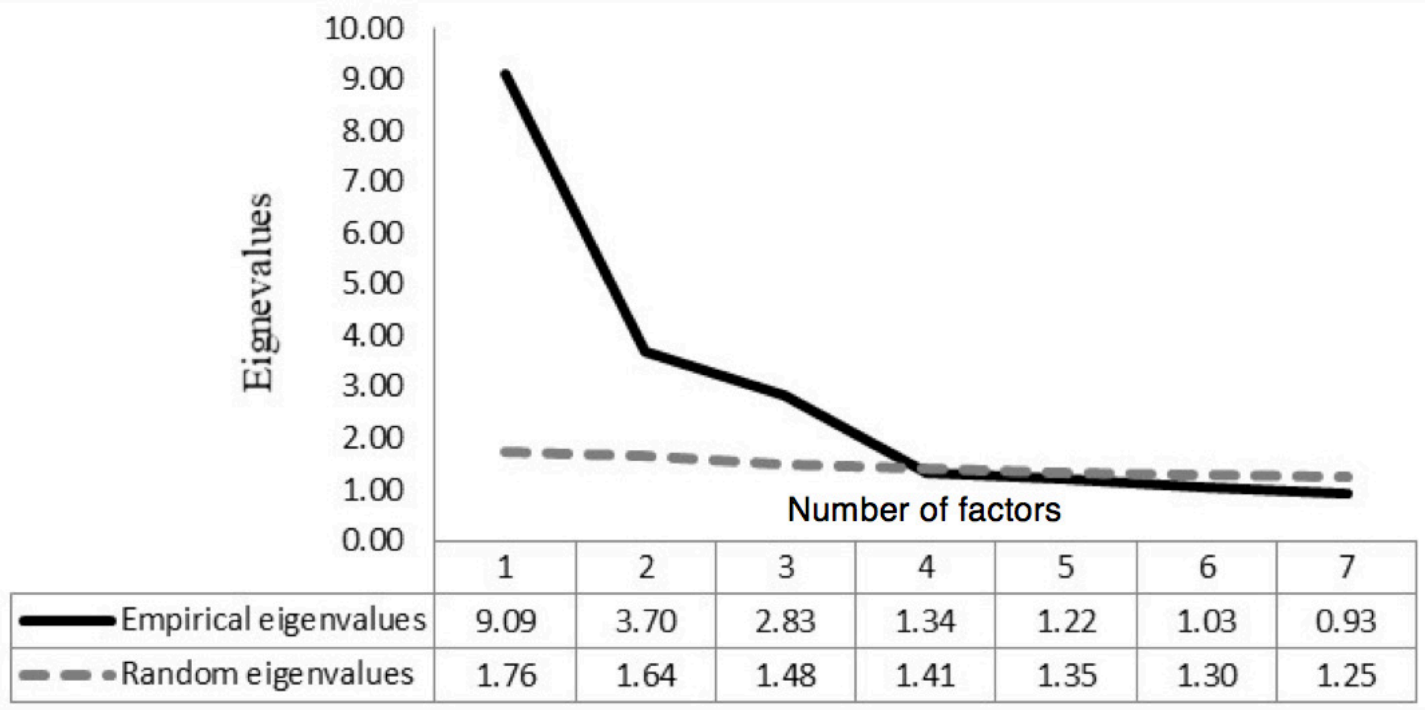

Figure 1 - Sediment graph of the parallel analysis for the academic motivation scale. São Paulo, SP, Brazil, 2014

Therefore, regarding the internal structure, the AMS could be represented in this study by three factors. Table 2 shows the estimated psychometric parameters for the items/factors.

When analyzing the items grouped by AMS factors based on the original proposal presented in Table 1, each factor corresponded to a different type of motivation:
Factor 1 corresponded to Extrinsic Motivation and grouped items were: 22, 08, 15, 01, 03, 10, 07, 24, 14, and 28. Factor 2 corresponded to Intrinsic Motivation, whose grouped items were: 11, 09, 16, 18, 25, 20, 04, 02, 06 and 13; and Factor 3 corresponded to Demotivation with the following grouped items: 26, 05,19 , and 12 .

Table 2 - Factor matrix of the academic motivation scale extracted by exploratory structural equation modeling (ESEM). São Paulo, SP, Brazil, 2014

\begin{tabular}{|c|c|c|c|c|}
\hline Item & $\begin{array}{c}\mathrm{F}^{*}{ }^{*} \\
\text { Extrinsic motivation }\end{array}$ & $\begin{array}{c}\mathrm{F}^{*} \\
\text { Intrinsic motivation }\end{array}$ & F3* Demotivation & $\mathbf{r}^{\text {itt }}$ \\
\hline 22 & 0.94 & -0.20 & -0.04 & 0.71 \\
\hline 8 & 0.88 & -0.13 & -0.03 & 0.73 \\
\hline 15 & 0.82 & -0.31 & 0.01 & 0.61 \\
\hline 1 & 0.68 & -0.11 & 0.02 & 0.54 \\
\hline 7 & 0.63 & 0.07 & 0.39 & 0.52 \\
\hline 24 & 0.62 & 0.00 & -0.41 & 0.42 \\
\hline 14 & 0.61 & 0.21 & 0.19 & 0.61 \\
\hline 28 & 0,54 & 0.30 & 0.28 & 0.53 \\
\hline 11 & -0.16 & 0.73 & -0.21 & 0.59 \\
\hline 9 & 0.10 & 0.72 & -0.20 & 0.69 \\
\hline 16 & 0.01 & 0.66 & -0.40 & 0.60 \\
\hline 18 & -0.14 & 0.64 & 0.07 & 0.49 \\
\hline 25 & -0.15 & 0.64 & 0.04 & 0.47 \\
\hline 20 & 0.10 & 0.58 & -0.05 & 0.54 \\
\hline 4 & -0.09 & 0.57 & -0.21 & 0.45 \\
\hline 2 & 0.02 & 0.55 & -0.30 & 0.50 \\
\hline 6 & 0.32 & 0.52 & -0.01 & 0.58 \\
\hline
\end{tabular}


(Table 2 continuation...)

\begin{tabular}{|c|c|c|c|c|}
\hline Item & $\begin{array}{c}\mathrm{F}^{*} \\
\text { Extrinsic motivation }\end{array}$ & $\begin{array}{c}\text { F2 }^{*} \\
\text { Intrinsic motivation }\end{array}$ & F3 $^{*}$ Demotivation & $\mathbf{r}^{\mathrm{itt}}$ \\
\hline 13 & 0.37 & 0.51 & 0.03 & 0.52 \\
\hline 26 & 0.10 & -0.02 & 0.93 & 0.63 \\
\hline 5 & -0.10 & -0.12 & 0.78 & 0.58 \\
\hline 19 & 0.09 & -0.21 & 0.78 & 0.54 \\
\hline 12 & -0.01 & 0.10 & 0.69 & 0,48 \\
\hline Number of items & 08 & 10 & 04 & \\
\hline Eigenvalue & 9.09 & 3.70 & 2.83 & \\
\hline Cronbach's alpha $(\alpha)$ & 0.84 & 0.84 & 0.71 & \\
\hline Composite reliability (CR) & 0.90 & 0.86 & 0.88 & \\
\hline $\begin{array}{l}\text { Average variance extracted } \\
\text { (AVE) }\end{array}$ & 0.53 & 0.38 & 0.64 & \\
\hline
\end{tabular}

*Correlation coefficients estimated at the level of $p \leq 0.05$; ${ }^{+}$item-total correlation coefficient.

Of all 28 items in the original scale, 22 items were retained in the factor analysis. Three items $(17,21,27)$ did not present factor loads equal to or greater than 0.40 in any of the three factors. Other three items $(03,10,23)$ were excluded due to theoretical and empirical difficulty to establish factor dominance in explaining the items - item 23, for example, presented 0.43 saturation in Factors 2 and 3. Thus, when compared to the theoretical expectation of grouping into higher order factors of the items, as illustrated in Table 1, three items that belonged to the extrinsic motivation subscale by identified regulation (17, 03 and 10), an item that belonged to intrinsic motivation to accomplish things (27) and another belonging to intrinsic motivation to know (21) were excluded.

In this study, the findings related to reliability of factors (Cronbach's alpha and composite reliability) of the groups of factors/types of motivation were, respectively: 0.84 and 0.90 for intrinsic motivation; 0.84 and 0.86 for extrinsic motivation; 0.71 and 0.88 for demotivation.

The three factors/types of motivation of the AMS were structurally related to each other in a significant matter, presenting different patterns. The relationship between Intrinsic and Extrinsic Motivation was positive and moderate (they shared about $20 \%$ of variance) and, the relationship between Demotivation and Intrinsic and Extrinsic Motivation was negative and weak (they shared $1 \%$ to $2 \%$ of variance, respectively), as indicated in Table 3. From the line of Extrinsic Motivation factor, the indicators of discriminant validity $(\sqrt{ } V M E)$ are observed diagonally for the modeled latent factors.

Although the AMS has been widely applied in its English version since its original proposal and considered one of the main instruments for measuring academic motivation in different countries, the Brazilian context lacked information about its dimensionality.
Table 3 - GEOMIN correlation and evidence of discriminant validity between modeled factors $(\mathrm{N}=205)$. São Paulo, SP, Brazil, 2014

\begin{tabular}{lccc}
\hline \multicolumn{1}{c}{ Factors } & $\begin{array}{c}\mathbf{F 1}^{*} . \\
\text { Extrinsic } \\
\text { Motivation }\end{array}$ & $\begin{array}{c}\mathbf{F 2}^{*} . \\
\text { Intrinsic } \\
\text { Motivation }\end{array}$ & $\begin{array}{c}\text { F3* }^{*} \\
\text { Demotivation }\end{array}$ \\
\hline $\begin{array}{l}\text { F1. Extrinsic } \\
\text { Motivation }\end{array}$ & 0.73 & & \\
$\begin{array}{l}\text { F2. Intrinsic } \\
\text { Motivation }\end{array}$ & 0.45 & 0.62 & 0.80 \\
F3. Demotivation & -0.15 & -0.11 & \\
\hline
\end{tabular}

"Correlation coefficients estimated at the level of $p \leq 0.05$

\section{Discussion}

Specialized literature shows that psychometric instruments must undergo successive assessments of dimensionality ${ }^{(34)}$, i.e., their internal structure, to ensure reliable data collection. They are also recommended to different contexts and moments. The evaluation of the validity evidence, based on the internal structure, proved to be necessary to check whether measurement attributes corresponded to the theoretical attributes. Therefore, the first question was what the test measured in order to later use it and accept it as a valid instrument to measure the academic motivation of undergraduate nursing students.

The result of parallel analyses did not support the extraction into seven factors according to the theoretical proposal of the authors of the scale ${ }^{(6-7)}$, since the matrix of empirical data of this study could be reduced to a maximum of three factors based on criteria found in the literature ${ }^{(29,35)}$.

The factor analyses in this study partially reproduced the theoretical model. Most of the item/factor relationships foreseen in the higher order structure ${ }^{(6-8)}$ were observed and the factor loads estimated at the level of $p \leq 0.05$ were considered "good" (above 0.55) and "excellent" (above 0.71 ), according to the proposed taxonomy ${ }^{(36)}$. 
The EFA based on the ESEM(27) aimed to find a factor matrix of the scale based on a spontaneous relationship between observable variables (items) and latent variables (factors) and presented robust evidence of the existence of a three-dimensional model with three types of motivation: one factor for intrinsic motivation, one for extrinsic motivation, and one for demotivation. The 3-factor model was used to prevent both overestimated factors and a larger number than adequate, which would produce nonparsimonious results, and underestimated factors and a lower number, thus causing loss of precious information ${ }^{(35)}$.

In the assessment of how all 28 items would interact, the configuration of three types/factors proved to be relevant to measure the motivation construct in the studied sample, in agreement with the SDT ${ }^{(1,2)}$. Thus, this study could attest a parsimonious alternative to the original version of the scale, with a valid reliable configuration in three factors of a higher order: Extrinsic Motivation, Intrinsic Motivation, and Demotivation.

The structure of seven and six factors was replicated in Brazil; however, the study used a modified version of the AMS for factor extraction and a principal component analysis $(P C A)^{(18)}$, which may have inflated the loading of items ${ }^{(37)}$.

Since the first version of the AMS, new statistical tests have been developed to identify the validity of measurement instruments in terms of theoretical constructs. In addition to replicating the scale in different contexts and moments, proper statistical tests based on EFA and CFA must be adopted, with psychometric modeling techniques and updated software. In general, studies aiming to evaluate the psychometric properties of instruments indiscriminately use programs and tools of reliability coefficients and PCA. Although they are common in usual statistical programs, these tools are not necessarily the most adequate techniques( ${ }^{(34)}$.

Another study conducted in Brazil evaluated the factor structure of the AMS through $\mathrm{EFA}^{(17)}$, with extraction of five factors and explanation of $61.8 \%$ variance, reproducing the structure model of the AMS in the subscales of extrinsic motivation and demotivation; however, the three subscales of intrinsic motivation were grouped into a single factor, similar to what occurred in this study. The theoretical model of seven factors was achieved only with CFA and absolute fit index RMSEA $=0.07 ;$ SRMR $=0.06$; and incremental fit indexes TLI (Tucker-Lewis Index) $=0.92 ; \mathrm{CFI}=0.93$ and was more adequate than the 5 -factor model (RMSEA $=0.09$; SRMR $=0.07 ;$ TLI $=0.90 ;$ CFI $=0.89)$. However, that study ${ }^{(17)}$ used Pearson's matrix, which usually identifies relationships between metric variables. For the AMS, since it is an ordinal scale, its relations are better identified using the polychoric correlation coefficient. Pearson's correlation tends to underestimate the correlation between items with ordinal/categorical responses and overestimate the number of factors in exploratory factor analyses(27-28).

In short, the adoption of robust criteria for the extraction of factors could explain the difference in the results found in the number of factors extracted, both in the Brazilian context ${ }^{(15,17,21)}$ and scale application in English $(7,19,38)$ and other languages into which it has been translated, including Norwegian ${ }^{(9)}$, Spanish ${ }^{(10)}$, Chinese $^{(12)}$, and Turkish ${ }^{(13)}$. It is noteworthy that most studies cited here used CFA in their assessments ${ }^{(7-10,12-15,17-19)}$.

As seen in the results of this study, other studies also proposed a new reconfiguration of the AMS by EFA, with the extraction of four factors: demotivation, extrinsic motivation by external regulation, extrinsic motivation by identified regulation, and intrinsic motivation, confirming the results by CFA, with proper validity and reliability and significant losses in models of one, two and three factors ${ }^{(39)}$. Other studies also pointed out inconsistencies in the number of factors, with extraction of five factors, in which the three types of intrinsic motivation were grouped into a single factor ${ }^{(20,40)}$, and extraction of three factors ${ }^{(41)}$. In a study with Lebanese medical students, PCA was used and the results showed the items converged into a 3-factor solution with explanation of $81.51 \%$ of total variance ${ }^{(11)}$.

In an assessment of the psychometric properties of the instrument with Chilean students of Dentistry ${ }^{(10)}$ and students of the health vocational course and social care course in Norway ${ }^{(9)}$ by CFA, the researchers confirmed a 7-factor model. In Argentina, two versions of the instrument were applied with high school and university students, and the results also reproduced the 7-factor model(14). In a revised version in Spanish ${ }^{(16)}$ that included the subscale extrinsic motivation by integrated regulation in the AMS from the original version(6), applied to Pedagogy students by CFA, the results showed acceptable adjustment indexes of the new structure, with eight factors $^{(16)}$. The authors proposed the inclusion of a factor previously suppressed in the $\mathrm{AMS}^{(7,8)}$ : extrinsic motivation by integrated regulation, to obtain an instrument that would allow the measurement of all motivation regulations proposed by $\mathrm{SDT}^{(1-2)}$ in the educational context in Spain.

When assessing the reliability of the scale factors used in this study, previous studies used the Cronbach's alpha index, considering the following satisfactory values: 0.48 to $0.98^{(11)}, 0.62$ to $0.82^{(7)}, 0.65$ to $0.83^{(10)}, 0.68$ to $0.83^{(21)}, 0.70$ to $0.86^{(16,18)}, 0.74$ to $0.92^{(17)}, 0.77$ to $0.90^{(19)}, 0.79$ to $0.86^{(38)}$. The reliability of the factors by Cronbach's alpha and the composite reliability were considered satisfactory in our study, according to the parameters reported in the literature ${ }^{(32-33)}$.

Regarding the pattern of item grouping, foreseen in the theoretical model in three factors of a higher order, 
it was empirically reproduced satisfactorily. Regarding the structural relationship between the factors/types of motivation, they were significantly related to different patterns. The relationship between intrinsic motivation and extrinsic motivation was positive and moderate (20\% variance), indicating that, as one type of motivation increases, the other tends to increase as well. On the other hand, the relationship between demotivation and intrinsic and extrinsic motivation was negative and weak ( 1 to $2 \%$ variance, respectively), indicating that, as demotivation decreases, the factors/types of intrinsic and extrinsic motivation tend to increase ${ }^{(42)}$.

Regarding the existence of the self-determination continuum and motivation ${ }^{(1,6-8)}$ seen as a significant positive correlation between intrinsic and extrinsic motivation and a negative correlation between intrinsic motivation and demotivation, the results confirmed the findings of other studies $^{(15,17,22)}$ and the theoretical model ${ }^{(1,2)}$. However, in the English version of the scale, most studies did not confirm this hypothesis ${ }^{(6-8,18-19,39)}$, suggesting this construct pattern did not exist or was limited ${ }^{(19,39)}$.

This study also assessed to what extent each modeled latent variable (that is, the AMS factors) was different and how it could be distinguished from the others. One way to obtain this evidence is to assess whether the square root of VME ( $V$ VME) is greater than the estimated variance shared between the constructs, i.e., greater than the correlation between latent factors. The results in Table 3 show evidence that all three factors were properly discriminated in this study, according to the literature ${ }^{(43-44)}$.

Regarding the content of the items, although it was not the objective of this study, the author of this study agreed with other authors who suggested that such content should be reviewed according to criteria recommended in the literature in order to make it more precise $^{(17)}$ and that the scale has to be revised and updated as a measurement tool(15,18-19,22). Although it is still one of the main instruments of academic motivation measurement today ${ }^{(45,46)}$, this study found the scale has to be improved, since the measurement attributes did not fully correspond to the theoretical attributes.

Specifically in the Portuguese version for the Brazilian context, the AMS should be explored more rigorously in the process of translation, cross-cultural adaptation, equivalence and frequency of terms, including reverse translation, not previously described ${ }^{(23)}$. A simple translation of the items does not ensure the maintenance of the original construct. Future studies could include a sequence with a cross-cultural adaptation and a more robust analysis of the factor structure ${ }^{(25)}$.

In the other countries where translated versions were used or in the contexts where the English version of the AMS was applied, the adoption of other analysis resources is suggested, that is, besides the CFA, ESEM is recommended as it allows the integration of structural equation modeling and EFA in a single analysis ${ }^{(27)}$.

Through ESEM this study presented different outcomes from previous studies that assessed the psychometric properties of the AMS with the determination of a 3-factor model according to the reference in the subject(27). Although the three factors observed the theoretical groupings of higher order of the AMS (extrinsic motivation, intrinsic motivation, and demotivation), it was not possible to show the scale refining into subfactors; in other words, there was no differentiation of the extrinsic motivation subscales in three types (extrinsic motivation by identified regulation, introjected regulation, and external regulation) and no differentiation of intrinsic motivation in three types (intrinsic motivation to know, to accomplish things, and to experience stimulation). In practical and applied terms, for the studied sample, the construct of academic motivation was only identified in the superior theoretical grouping.

Study limitations referred to the application of the AMS in a single moment of the course from a single field (nursing), which limits the generalization to other courses and students. The validity of measurement instruments and, in this case, the AMS, must be tested with other samples, preferably using analysis methods and software that are more appropriate to the categorical data, as seen in the study scale, either in the Brazilian context or in other countries, with students from different courses and other educational levels, to expand the evidence of validity of the motivation measurement instrument.

\section{Conclusion}

The dimensionality of the AMS produced a model with three factors/types of motivation, factors of a higher order in agreement with that proposed in the Self-Determination Theory and was considered a parsimonious alternative to the original version, which proposes the measurement of seven factors. The results showed that the AMS presents evidence of satisfactory reliability and validity for three types of motivation: intrinsic motivation, extrinsic motivation, and demotivation, with robust evidence of adjustment and proper discrimination.

The findings supported the existence of the autonomy continuum, with significant positive correlations between intrinsic motivation and extrinsic motivation and a negative correlation between intrinsic motivation and demotivation.

Although new evidence of the psychometric quality of the AMS has been obtained, with the limitation of measuring three different types of motivation among nursing students, investigations with larger and more 
diversified samples are required so that the invariance properties of the scale can be properly investigated.

\section{References}

1. Deci EL, Ryan RM. Intrinsic motivation and selfdetermination theory in human behavior. New York: Plenum Press; 1985.

2. Deci EL, Ryan RM. The support of autonomy and the control of behavior. J Pers Soc Psychol. [Internet]. 1987 Apr 30 [cited Jul 2, 2019];53(6):1024-37. Available from: https://www.ncbi.nlm.nih.gov/pubmed/3320334

3. Kusurkar RA, Cate TJT, Vos CMP, Westers P, Croiset G. How motivation affects academic performance: a structural equation modelling analysis. Adv in Health Sci Educ. [Internet]. 2013 [cited Apr 4, 2020];18(1):5769. Available from: https://www.ncbi.nlm.nih.gov/pmc/ articles/PMC3569579/

4. Miguel MS, Lizaso I, Hermosilla D, Alcover CM, Goudas $M$, Arranz-Freijó E. Preliminary validation of the Perceived Locus of Causality scale for academic motivation in the context of university studies (PLOC-U). Br J Educ Psychol. [Internet]. 2017 May 25 [cited Apr 4, 2020];87(4):55872. Available from: https://doi.org/10.1111/bjep.12164 5. Wouters A, Croiset G, Schripsema NR, Cohen-Schotanus J, Spaai GWG, Hulsman RL, et al. A multi-site study on medical school selection, performance, motivation and engagement. Adv in Health Sci Educ. [Internet]. 2017 Jan 4 [cited Apr 4, 2020];22:447-62. Available from: https:// link.springer.com/article/10.1007\%2Fs10459-016-9745-y 6. Vallerand RJ, Blais MR, Brière NM, Pelletier LG. Construction et validation de l'échelle de Motivation en Education (EME). Canad J Sci Comp. [Internet]. 1989 Sep 26 [cited Jul 2, 2019];21(3):323-49. Available from: http://selfdeterminationtheory.org/SDT/documents/1989_ VallerandBlaisBrierePelletier_CJBSRCSC.pdf

7. Vallerand RJ, Pelletier LG, Blais MR, Brière NM, Senécal $C$, Vallières EF. The academic motivation scale: a measure of intrinsic, extrinsic, and amotivation in education. Educ Psychol Measur. [Internet]. 1992 Dec 10 [cited Jul 2, 2019];52(4):1003-17. Available from: https://doi. org/10.1177/0013164492052004025

8. Vallerand RJ, Pelletier LG, Blais MR, Brière NM, Senécal $C$, Vallières EF. On the assessment of intrinsic, extrinsic and amotivation in education: evidence on the concurrent and construct validity of the academic motivation scale. Educ Psychol Measur. [Internet]. 1993 Mar 1 [cited Jul 2, 2019];53(1):159-72. Available from: https://doi. org/10.1177/0013164493053001018

9. Utvær BKS, Haugan G. The Academic Motivation Scale: Dimensionality, Reliability, and Construct Validity Among Vocational Students. NJVET. [Internet]. 2016 Jun 2 [cited Jul 2, 2019];6(2):17-45. Available from: http://www.
njvet.ep.liu.se/article.asp?DOI=10.3384/njvet. 2242 458X.166217

10. Orsini C, Binnie V, Evans P, Ledezma P, Fuentes F, Villegas MJ. Psychometric validation of the academic motivation scale in a dental student sample. J Dent Educ. [Internet]. 2015 Aug 1 [cited Jul 2, 2019];79(8):97181. Available from: https://www.ncbi.nlm.nih.gov/ pubmed/26246537

11. Sarks AS, Hallit S, Hajj A, Kechichian A, Sarkis DC, Sarkis $A$ et al. Lebanese students' motivation in medical school: does it change throughout the years? A crosssectional study. BMC Med Educ. [Internet]. 2020 Mar 31 [cited Apr 4, 2020];20:94. Available from: https:// bmcmededuc.biomedcentral.com/track/pdf/10.1186/ s12909-020-02011-w

12. Zhang B, Li YM, Li J, Li Y, Zhang $H$. The revision and validation of the Academic Motivation Scale in China. J Psychoeduc Assess. [Internet]. 2016 Feb 1 [cited Apr 4, 2020];34(1):15-27. Available from: https://journals. sagepub.com/doi/abs/10.1177/0734282915575909

13. Can G. Turkish version of the Academic Motivation Scale. Psychol Rep. [Internet]. 2015 Apr 1 [cited Apr 4, 2020];116(2):388-408. Available from: https://www. ncbi.nlm.nih.gov/pubmed/25826436

14. Stover JB, Iglesia G, Boubeta AR, Liporace MF. Academic motivation scale: adaptation and psychometric analyses for high school and college students. Psychol Res Behav Manag. [Internet]. 2012 Jul 25 [cited Jul 2, 2019];5:71-83. Available from: https://www.ncbi.nlm. nih.gov/pmc/articles/PMC3414248/

15. Guimarães SER, Bzuneck JA. Psychometric properties of an instrument for assessing the motivation of university. Cienc Cogn. [Internet]. 2008 Mar 1 [cited Jul 2, 2019];13(1):101-13. Available from: http:// pepsic.bvsalud.org/scielo.php?script=sci_arttext\&pid $=\mathrm{S} 1806-58212008000100011$

16. Burgueño R, Sicilia A, Medina-Casaubón J, AlcarazIbáñez $M$, Lirola MJ. Academic motivation scale revised. Inclusion of integrated regulation to measure motivation in initial teacher education. An Psicol-Spain [Internet]. 2017 Jul 21 [cited Apr 4, 2020];33(3):670-679. Available from: http://dx.doi.org/10.6018/analesps.33.3.249601 17. Davoglio TR, Santos BS, Lettnin CC. Validity of academic motivation scale for the Brazilian higher education students. Ensaio Aval Pol Públ Educ. [Internet]. 2016 Sep 1 [cited Jul 2, 2019];24(92):522-45. Available from: http://www.scielo.br/scielo.php?script $=$ sci_ abstract\&pid =S0104-40362016000300522\&Ing=en\&nr $\mathrm{m}=\mathrm{iso} \& \mathrm{tlng}=\mathrm{en}$

18. Cokley KO, Bernard N, Cunningham D, Motoike J. A psychometric investigation of the academic motivation scale using a United States sample. Measure Eval Couns 
Dev. [Internet]. 2001 Jul 3 [cited Jul 2, 2019];34(2):10919. Available from: https://eric.ed.gov/?id=EJ634347

19. Fairchild AJ, Horst SJ, Finney SJ, Barron KE. Evaluating new and existing validity evidence for the academic motivation scale. Contemp Educ Psychol. [Internet]. 2005 Jul 3 [cited Jul 2, 2019];30(3):331-58. Available from: https://www.sciencedirect.com/science/article/pii/ S0361476X04000736

20. Grouzet ME, Otis N, Pelletier LG. Longitudinal crossgender factorial invariance of the academic motivation scale. Struct Equ Modeling. [Internet]. 2006 Nov 19 [cited Jul 2, 2019];13(1):73-98. Available from: http:// selfdeterminationtheory.org/SDT/documents/2006_ GrouzetOtisPelletier_SEM.pdf

21. Viana GS. Attitude and motivation in relation to the academic performance of undergraduate students from statistics courses in business administration: the formation of clusters. Adm Ens Pesq. [Internet] 2012 Sep 10 [cited Aug 15, 2019];13(3):523-58. Available from: https:// raep.emnuvens.com.br/raep/article/view/88/50

22. Cokley KO. Examining the validity of the academic motivation scale by comparing scale construction to selfdetermination theory. Psychol Rep. [Internet]. 2000 Apr 1 [cited Jul 2, 2019];86(2):560-4. Available from: https:// www.ncbi.nlm.nih.gov/pubmed/10840913

23. Sobral DT. Learner's motivation in medical studies: use of the academic motivation scale. Psic Teor Pesq. [Internet]. 2003 Apr 1 [cited Jul 2, 2019];19(1):2531. Available from: http://www.scielo.br/pdf/ptp/v19n1/ a05v19n1

24. Souza AC, Alexandre NMC, Guirardello EB. Psychometric properties in instruments evaluation of reliability and validity. Epidemiol Serv Saúde. [Internet]. 2017 Sep 1 [cited Apr 4, 2020];26(3):64959. Available from: https://doi.org/10.5123/s167949742017000300022

25. Borsa JC, Damásio BF, Bandeira DR. Cross-Cultural Adaptation and Validation of Psychological Instruments: Some Considerations. Paidéia. [Internet]. 2012 Dec 1 [cited Jul 2, 2019];22(53):423-32. Available from: http:// www.scielo.br/scielo.php?script=sci_arttext\&pid=S0103$863 \times 2012000300014$

26. American Educational Research Association, American Psychological Association, National Council on Measurement in Education. Standards for Educational and Psychological Testing. Washington (DC): AERA Publications; 2014.

27. Asparouhov T, Muthén B. Exploratory Structural Equation Modeling. Multidisciplinary J. [Internet]. 2009 Jul 1 [cited Jul 2, 2019];16(3):397-438. Available from: https://www.tandfonline.com/doi/ abs/10.1080/10705510903008204
28. Muthén LK, Muthén BO. Mplus user's guide. 8th ed. Los Angeles: Muthén \& Muthén; 2017.

29. Horn JL. A rationale and technique for estimating the number of factors in factor analysis. Psychometrika. [Internet]. 1965 Jun 3 [cited Jul 2, 2019];30(1):17985. Available from: https://www.ncbi.nlm.nih.gov/ pubmed/14306381

30. Kline RB. Principles and practice of structural equation modeling. $4^{\text {th }}$ ed. New York, London: The Guilford Press; 2016.

31. Rios J, Wells C. Validity evidence based on internal structure. Psicothema. [Internet]. 2014 Oct 10 [cited Jul 2, 2019];26(1):108-16. Available from: https://www. ncbi.nlm.nih.gov/pubmed/24444738

32. Hair JF, Black WC, Babin BJ, Anderson RE, Tathan RL. Análise multivariada de dados. 7. ed. Porto Alegre: Bookman; 2010.

33. Peterson RA, Kim Y. On the relationship between coefficient alpha and composite reliability. J Appl Psychol. [Internet]. 2013 Jan 1 [cited Apr 4, 2020];98(1):194-8. Available from: https://doi.org/10.1037/a0030767

34. Borsboom D. The attack of the psychometricians. Psychometrika. [Internet]. 2006 Sep 1 [cited Jul 2, 2019];71(3):425-40. Available from: https://www.ncbi. nlm.nih.gov/pmc/articles/PMC2779444/

35. Damásio BF. Uses of exploratory factorial analysis in psychology. Aval Psicol. [Internet]. 2012 May 1 [cited Jul 2, 2019];11(2):213-28. Available from: http://pepsic. bvsalud.org/pdf/avp/v11n2/v11n2a07.pdf

36. Comrey AL, Lee HB. A first course in factor analysis. $2^{\text {nd }}$ ed. Hillsdale: Lawrence Erlbaum; 1992.

37. Costello $A B$, Osborne JW. Best practices in exploratory factor analysis: four recommendations for getting the most from your analysis. Pract. Assess. Res. Eval. [Internet]. 2005 Jul 1 [cited Jul 2, 2019];10(7):1-9. Available from: http://citeseerx.ist.psu.edu/viewdoc/download?doi=10.1

\section{$.1 .110 .9154 \&$ rep $=$ rep $1 \&$ type $=$ pdf}

38. Smith KJ, Davy JA, Rosenberg DL. An examination of the validity of the academic motivation scale with a united states business student sample. Psychol Rep. [Internet]. 2010 Apr 10 [cited Jul 2, 2019];106(2):323-41. Available from: https://journals.sagepub.com/doi/10.2466/ pro.106.2.323-341

39. Smith KJ, Davy JA, Rosenberg DL. An empirical analysis of an alternative configuration of the academic motivation scale. Assess Educ. [Internet]. 2012 Jan 13 [cited Jul 2, 2019];19(2):231-50. Available from: https:// eric.ed.gov/?id=EJ962957

40. Pisarik CT. Motivational orientation and burnout among undergraduate college students. Coll Stud J. [Internet]. 2009 Dec 1 [cited Jul 2, 2019];43(4):123852. Available from: https://eric.ed.gov/?id=EJ872339 
41. Baker SR. Intrinsic, extrinsic, and amotivational orientations: their role in university adjustment, stress, well-being, and subsequent academic performance. Curr Psychol. [Internet]. 2004 Sep 1 [cited Jul 2, 2019];23(3):189-202. Available from: https://link. springer.com/article/10.1007/s12144-004-1019-9

42. Hemphill JF. Interpreting the magnitudes of correlation coefficients. Am Psychol. [Internet]. 2003 Jan 1 [cited Jul 2, 2019];58(1):78-80. Available from: https://psycnet. apa.org/record/2003-02034-011

43. Farrell AM. Insufficient discriminant validity: a comment on Bove, Pervan, Beatty and Shiu (2009). J Bus Res. [Internet]. 2010 Mar 1 [cited Jul 2, 2019];63(3):3247. Available from: https://www.sciencedirect.com/science/ article/abs/pii/S0148296309001453

44. Fornell C, Larcker DF. Evaluating structural equation models with unobservable variables and measurement error. JMR. [Internet]. 1981 Feb 1 [cited Jul 2, 2019];18(1):39-50. Available from: https://journals. sagepub.com/doi/abs/10.1177/002224378101800104 45. Del-Ben CM, Shuhama R, Costa MJ, Troncon LEA. Effect of changes to the formal curriculum on medical students' motivation towards learning: a prospective cohort study. Sao Paulo Med J. [Internet]. 2019 Jun 10 [cited Jun 10, 2020];137(2):112-8. Available from: https://www.scielo.br/pdf/spmj/v137n2/1806-9460spmj-1516-3180-2018-0264090119.pdf

46. Secchin LSB, Ezequiel OS, Vitorino LM, Lucchetti ALG, Lucchetti G. Implementation of a Longitudinal Mentorship Program for Quality of Life, Mental Health, and Motivation of Brazilian Medical Students. Acad Psychiatry. [Internet]. 2020 Apr 1 [cited Jun 10, 2020];44(2):200-4. Available from: https://pubmed.ncbi.nlm.nih.gov/31741305/

\section{Authors' Contribution:}

Study concept and design: Geisa Colebrusco de Souza, Maria Madalena Januário Leite. Obtaining data: Geisa Colebrusco de Souza. Data analysis and interpretation: Geisa Colebrusco de Souza, Everson Meireles, Vera Lúcia Mira, Maria Madalena Januário Leite. Statistical analysis: Geisa Colebrusco de Souza, Everson Meireles, Vera Lúcia Mira, Maria Madalena Januário Leite. Drafting the manuscript: Geisa Colebrusco de Souza, Everson Meireles, Vera Lúcia Mira, Maria Madalena Januário Leite. Critical review of the manuscript as to its relevant intellectual content: Geisa Colebrusco de
Souza, Everson Meireles, Vera Lúcia Mira, Maria Madalena Januário Leite.

All authors approved the final version of the text.

Conflict of interest: the authors have declared that there is no conflict of interest.
Received: Oct 31 st 2019 Accepted: Aug 21 2020

Associate Editor: Ricardo Alexandre Arcêncio

Copyright @ 2021 Revista Latino-Americana de Enfermagem This is an Open Access article distributed under the terms of the Creative Commons (CC BY).

This license lets others distribute, remix, tweak, and build upon your work, even commercially, as long as they credit you for the original creation. This is the most accommodating of licenses offered. Recommended for maximum dissemination and use of licensed materials. 